\title{
Aprendizado de Máquina Quântica com Rede Neural Artificial Aplicado ao Problema de Coloração de Grafos
}

\author{
Flávia Janine R. Béo ${ }^{1}$, Karla Vittori ${ }^{1}$ \\ ${ }^{1}$ Centro de Matemática, Computação e Cognição - Universidade Federal do ABC (UFABC) \\ Santo André - SP - Brazil \\ flavia.beo@ufabc.edu.br, karla.vittori@ufabc.edu.br
}

\begin{abstract}
The problem of coloring graphs is to assign colors to certain elements of a graph, subject to certain conditions. When characterized as a combinatorial optimization problem, it has applicability to a wide range of areas that involve partitioning and conflicts, comprising different scheduling and allocations, such as, for example, tasks, channels, networks, events and routes. The considered problem, constituted by a graph with 4 vertices, demonstrated the potential of quantum machine learning with artificial neural networks proposed in the resolution of a combinatorial optimization problem, which obtained superior results in relation to those presented by the classic artificial neural network, implemented in a classic computer, with respect to the processing time and the accuracy of the considered neural network.
\end{abstract}

Resumo. O problema de coloração de grafos consiste em atribuir cores a certos elementos de um grafo, sujeito a determinadas condições. Ao se caracterizar como um problema de otimização combinatória, ele possui aplicabilidade a uma vasta gama de áreas que envolvem particionamento e conflitos, compreendendo escalonamentos e alocações diversas, como, por exemplo, de tarefas, canais, redes, eventos e rotas. O problema considerado, constituído por um grafo com 4 vértices, demonstrou o potencial do aprendizado de máquina quântica com redes neurais artificiais proposto na resolução de um problema de otimização combinatória, o qual obteve resultados superiores em relação àqueles apresentados pela rede neural artificial utilizada, implementada em um computador clássico, com relação ao tempo de processamento e à acurácia da rede neural clássica.

\section{Introdução}

Em aplicações de trabalhos relacionados da literatura, já foram feitas implementações de Aprendizado de Máquina (AM) quântica para solucionar o problema de coloração de grafos com comparação entre técnicas que envolvem computação clássica e quântica [Campbell et al. 2019]. Utilizando-se de técnicas com processamento quântico, o objetivo desta pesquisa é a execução de um algoritmo de Inteligência Artificial [Sutton and Barto 2011] em um computador quântico para a resolução de um problema de coloração de grafos, em uma implementação de um algoritmo híbrido. A intenção é demonstrar o ganho em performance, baseando-se em diferentes métricas, como o tempo de execução do algoritmo implementado e a qualidade da solução por ele encontrada, levando em consideração a execução simulada do seu funcionamento em um computador quântico. Utilizam-se então, duas RNAs (Redes Neurais Artificiais), uma clássica e 
outra híbrida, para uma comparação não apresentada anteriormente em trabalhos correlatos mencionados. Além disso, foi proposta uma solução para o problema envolvendo uma RNA híbrida, que foi implementada com uma camada interna quântica, usando as instâncias simuladas de computadores quânticos oferecidas por uma plataforma de computação em nuvem.

Os experimentos foram realizados no IBM $Q$ Experience, com instâncias simuladas do IBM $Q$, as quais podem ser utilizadas através de bibliotecas disponíveis para diferentes aplicações da Computação Quântica. Também foi utilizada nesta pesquisa, a biblioteca de código fonte aberto denominada Tensorflow, que possui ferramentas para construção de modelagens híbridas clássico-quântico de aprendizado de máquina, em particular de Redes Neurais Artificiais. Os grafos utilizados nos experimentos realizados possuem quatro vértices, pelo fato de representarem as entradas da camada de processamento quântico simulado, uma vez que esta possui 4 Qbits em seu circuito. Foram gerados aleatoriamente 582 grafos para a fase de treino e 180 para a fase de teste das redes, sem restrições em relação às arestas. Assim, verificou-se o potencial da simulação em um Computador Quântico de uma técnica de Inteligência Artificial para a resolução de um problema de otimização combinatória relevante na comunidade científica, uma vez que ele pode ser aplicado na resolução de problemas de diversas áreas. Além disso, toda a implementação feita para esta pesquisa estará disponível em código de fonte aberto, que poderá ser utilizado para futuras pesquisas.

\section{Implementações}

\subsection{Rede Neural Artificial Clássica}

A inspiração para as implementações foi o trabalho dos autores que apresentaram uma Rede Neural para solução da coloração de grafos e para encontrar o número cromático [Prates et al. 2019]. Prates e colaboradores obtiveram no procedimento de treino $82 \%$ de assertividade, utilizando de um conjunto de dados dividido em 128 lotes e 5300 épocas. Para produzir o número cromático, os testes foram feitos com 4096 instâncias de grafos que seguiram a mesma distribuição do treino. Ao final dos testes, a RNA teve resultados de assertividade em torno de $86 \%$ sobre a coloração desejada nos grafos. Esta RNA foi implementada, e teve ambas as fases de treino e teste em um hardware de processamento 2,3 GHz 8-Core Intel Core i9, com a mesma versão de código disponibilizada pelos autores.

\subsection{Implementação da Rede Neural Quântica}

A Rede Neural Quântica implementada nesta pesquisa foi composta por uma camada escondida quântica em um circuito de 4 Qbits disponíveis para precisão dos dados de entrada, simulada no computador quântico provido pela IBM, IBM Quantum Experience, usando a função de ativação softmax em suas camadas clássicas. O modelo de RNA em que este circuito foi baseado, foi a RNA Quântica Qbit, seguindo a implementação classificada por [Jeswal and Chakraverty 2019].

Na Figura 1, pode ser observada uma arquitetura da RNA quântica implementada nesta pesquisa, descrevendo as bibliotecas utilizadas e as camadas presentes nela. Cada camada representada pelas caixas coloridas, vê-se na legenda abaixo da figura (quadro branco com os ícones), a tecnologia que foi utilizada como ferramenta para 
implementação da mesma. As entradas da RNA foram os valores da matriz de adjacência de cada grafo, que passaram pela camada de normalização, seguida pela camada quântica (Quantum L na figura), envolvida por duas camadas densas, (Dense 1, e Dense 2 na figura). Por fim, a camada de saída $Y$, onde é obtido o número cromático do grafo.

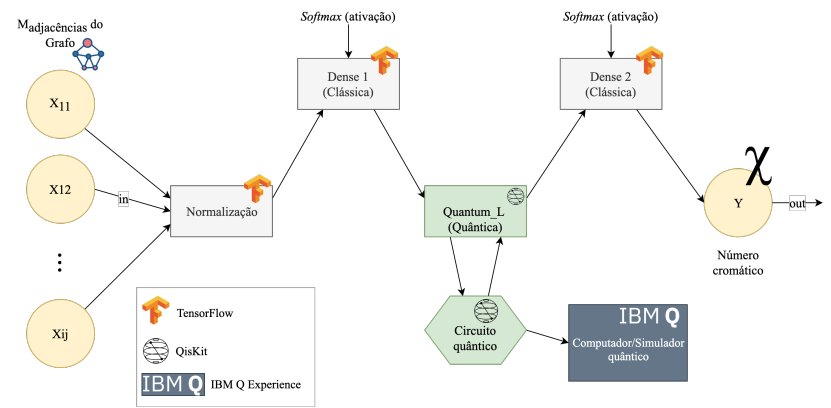

Figura 1. Esquema de arquitetura implementado. Camadas da RNA quântica e ícones de cada biblioteca utilizada.

A modelagem da RNA quântica teve como primeiro passo a construção da camada quântica linear que receberia as entradas após a primeira camada clássica da rede. Portanto, as entradas clássicas criadas no conjunto de dados tiveram de ser encodificadas, ou seja, os estados foram preparados para serem processados pelo circuito quântico. A preparação dos estados para o circuito de 4 Qbits utilizados na camada quântica, foi definida em tempo linear e estabelecida seguindo uma rotina de Mottonen [Bergholm et al. 2005], ou seja, mapeando um estado arbitrário $\mid \psi>$ para o estado fundamental $\mid 0 \ldots 0>$. Então cada uma das operações foi invertida e aplicada na ordem inversa.

O principal ponto dessa preparação foi controlar uma rotação em um $Q b i t q_{s}$ por todos os estados possíveis dos Qbits, fazendo uma rotação diferente para cada ramificação possível da superposição em torno dos vetores que representam as portas do circuito. $O$ aprendizado acontece nas atualizações dos ângulos desses vetores a cada iteração através dos conjuntos de dados.

\section{Resultados}

Para os testes dos algoritmos, foi utilizado um conjunto de dados dedicado apenas para teste com 180 grafos distintos, em que cada entrada possui a matriz de adjacências, e o número cromático correspondente ao grafo. Na Tabela 1, são apresentados os números extraídos dos testes e treinos feitos com ambas as redes. A RNA com processamento quântico em uma das suas camadas proposta nesse trabalho é chamada de QRNA. E a RNA puramente clássica, executada para fins de comparação, GRNA.

Os tempos de treino observados têm diferença significativa entre si, e algumas considerações a serem feitas, como o número de épocas da GRNA ser maior do que o número de épocas da $Q R N A$. O tempo total considerado foi desde o início até o final do ciclo completo de todas as épocas de treino. Tem-se que 90 épocas da RNA clássica, foram executadas em aproximadamente 30 minutos no total, e que 50 épocas da RNA quântica, em 25. Por outro lado, a convergência da rede $Q R N A$ foi mais rápida para o treino, obtendo assertividade de quase $98 \%$ máxima em menos épocas que a RNA clássica. Ambas com o mesmo conjunto de grafos, apresentaram diferença significativa em tempo e assertividade obtida, sendo de quase $10 \%$ maior para a $Q R N A$. Para os conjuntos de teste, o 
Tabela 1. Comparação dos resultados de teste e treino entre as RNAs clássica (G RNA) e quântica (Q RNA).

\begin{tabular}{|c|c|c|c|c|c|}
\hline & $\begin{array}{l}\text { Treino } \\
\text { Épocas }\end{array}$ & Vértices & $\begin{array}{c}\text { Tamanho do } \\
\text { Conjunto }\end{array}$ & $\begin{array}{l}\text { Acurácia } \\
\text { Máxima }\end{array}$ & Tempo \\
\hline Q RNA & 50 & 4 & 582 & $97,92 \%$ & $\sim 25 \mathrm{~m}$ \\
\hline \multirow[t]{3}{*}{ G RNA } & 90 & 4 & 582 & $87,58 \%$ & $\sim 30 \mathrm{~m}$ \\
\hline & Testes & & & & \\
\hline & & Vértices & $\begin{array}{c}\text { Tamanho do } \\
\text { Conjunto }\end{array}$ & $\begin{array}{l}\text { Acurácia } \\
\text { Máxima }\end{array}$ & Tempo \\
\hline Q RNA & & 4 & 180 & $96,62 \%$ & $5205.732 \mathrm{~ms}$ \\
\hline G RNA & & 4 & 180 & $82,00 \%$ & $131216.000 \mathrm{~ms}$ \\
\hline
\end{tabular}

tempo foi medido para a obtenção de resultados para todos os 180 grafos do conjunto, com o modelo já treinado para ambas. A diferença de assertividade se manteve consistente, como se pode observar na Tabela 1, com o tempo de obtenção dos resultados do modelo quântico menor, mesmo que os dois sejam tempos obtidos na casa dos milissegundos.

\section{Conclusões}

Apesar de os desafios existirem devido a ruídos e limitações, usar Qbits como neurônios artificiais evita o uso de nós nas camadas ocultas como na RNA clássica. Com isso, o tamanho dos parâmetros a serem otimizados diminui, pois não há conexões a serem estabelecidas entre as camadas. A própria medida quântica atua como uma função de ativação que economiza o esforço computacional. Dessa forma, as únicas conexões de camadas para a implementação desta pesquisa foram entre as camadas que envolveram a camada quântica. Então, a RNA quântica utilizou de apenas alguns parâmetros para aprender os padrões nos dados. E o tempo de execução para encontrar a solução, pôde ser reduzido de um tempo polinomial $O\left(|V|^{2}\right)$ para linear $O(|V|)$ em relação à RNA clássica profunda de Prates e colaboradores. Os tempos de execução obtidos com a RNA quântica apresentaram melhora na casa de $10 \%$ em relação aos tempos da RNA clássica, para os conjuntos de dados produzidos e no escopo definido para os testes. Para trabalhos futuros, um tratamento para incorporação das entradas pode aumentar o número de vértices aceito pela RNA, como alternativa a um número maior de Qbits.

\section{References}

Bergholm, V., Vartiainen, J. J., Möttönen, M., and Salomaa, M. M. (2005). Quantum circuits with uniformly controlled one-qubit gates. Physical Review A, 71(5):052330.

Campbell, E., Khurana, A., and Montanaro, A. (2019). Applying quantum algorithms to constraint satisfaction problems. Quantum, 3:167.

Jeswal, S. and Chakraverty, S. (2019). Recent developments and applications in quantum neural network: a review. Archives of Computational Methods in Engineering, 26(4):793-807.

Prates, M., Avelar, P. H., Lemos, H., Lamb, L. C., and Vardi, M. Y. (2019). Learning to solve np-complete problems: A graph neural network for decision tsp. In Proceedings of the AAAI Conference on Artificial Intelligence, volume 33, pages 4731-4738.

Sutton, R. S. and Barto, A. G. (2011). Reinforcement learning: An introduction. 